\title{
Designing an Entrepreneurial Supply Chain Model during Disasters in Iran
}

\author{
Mojtaba Akbari ${ }^{1} \mathbb{D}$, Hossein Didehkhani $^{2} \mathbb{D}$, Samereh Shojaei ${ }^{2} \mathbb{D}$, Ahmad Mehrabian $^{2} \mathbb{D}$
}

Date of submission: 21 Dec. $2020 \quad$ Date of acceptance: 20 Jan. 2021

\section{Original Article}

\section{Abstract}

INTRODUCTION: Relief organizations, especially the Red Crescent, lack any specific entrepreneurial strategy and program for production, identification, and distribution of relief supplies. These organizations mainly focus on the preparation and distribution of supplies in times of crisis. In this regard, the present study aimed to design an entrepreneurial supply chain model with an emphasis on technology in 2020 in Iran.

METHODS: The present study was conducted based on a qualitative and quantitative design. In the first phase, some indicators were obtained by observing the current situation and interviewing 30 experts. Following that, the final model was achieved by considering all indicators and categorizing the topics. In the Delphi process, experts' interviews and theoretical consensus suggested some hypotheses. In other words, in the second phase, structural equation modeling was used to finalize the model. In the next stage, the final questionnaire was provided to 186 Red Crescent employees.

FINDINGS: After the analysis and extraction of the criteria from the interviews, components of the model were retrieved, and two questionnaires were designed. The first questionnaire was about supply chain management encompassing four main components of customer integrity, supplier integrity, internal integrity, and innovative orientation. The second questionnaire was related to technology, including seven components: personal characteristics, attitudinal factors, educational factors, technical factors, economic factors, environmental factors, as well as human and managerial factors. Considering the KMO value $(>0.7)$ and the significant value of the Bartlett Sphericity test, it can be concluded that the data are suitable for factor analysis. The model fit values all exceeded 0.9, indicating that the model has a "good fit. The path coefficients were significant for seven relationships at the level of 0.05 .

CONCLUSION: As evidenced by the obtained results, the supply chain in disasters requires experts' comprehensive approach and innovative perspectives. The tendency of countries to take innovative measures in disasters requires macro-policies at the national and regional levels. Therefore, all dimensions and aspects of the entrepreneurial supply chain in disasters must be considered in order to attain the final goal which is effective and efficient disaster management.

Keywords: Disasters; Entrepreneurship; Supply Chain; Technology.

How to cite this article: Akbari $M$, Didehkhani $H$, Shojaei S, Mehrabian A. Designing an

Entrepreneurial Supply Chain Model during Disasters in Iran. Sci J Rescue Relief 2021; 13(1):9-15.

\section{Introduction}

I ran is one of the most disaster-prone countries in the world. According to statistics, out of the 40 different types of natural disasters occurring across the globe, 31 types have been identified in Iran. The existence of such natural disasters in the country made Iran one of the top 10 disaster-prone countries in the world (1). Crisis management is a science seeking to find a way to prevent crises by systematic observation and analysis. Moreover, in the event of a crisis, it helps to take efficient measures with preparedness, efficient coping, organization,

1-PhD student, Department of Entrepreneurship, Aliabad Katoul Branch, Islamic Azad University, Aliabad Katoul, Iran

2-Assistant Professor, Department of Industries, Aliabad Katoul Branch, Islamic Azad University, Aliabad Katoul, Iran

3-Assistant Professor, Department of Management, Aliabad Katoul Branch, Islamic Azad University, Aliabad Katoul, Iran

Correspondence to: Hossein Didehkhani, Email:h.didehkhani@gmail.com 
coordination, and planning. $(2,3)$.

Crises are low probability, high severity events which present unprecedented demands to the organization and result in confusion (4). Although various organizations are involved in disaster and distribution of relief and medical supplies, the Red Crescent plays a major role in this regard. When disasters occur, they destruct infrastructure and dwellings; consequently, disaster-affected people will be in need of relief and medical supplies. Prompt and accurate distribution of relief and medical supplies relieve the suffering of victims and reduce the costs of relief organizations.

Entrepreneurial supply chains make a connection between customers and suppliers and include quality and growth in the context of innovation. An entrepreneurial supply chain, as well as innovation and growth, can be attained by opportunity identification, attempts to write a business plan, risk management, integration of entrepreneurial processes, and provision of chain investments (5). Today, due to the importance of economic activities based on the entrepreneurial approach, the selection and adoption of the type of paradigms and practical approaches in the economic field play a crucial role in the positive consequences and efficient performance of related organizations and companies.

To achieve a sustainable supply chain, the strategic level is one of the best steps to consider sustainability criteria $(6,7)$. Supply chain management as a practical approach can be effective in the provision and optimization of economic resources in various processes, such as crisis management and provision of the social, health, medical, and other needs of the affected community.

It is worth noting that the traditional view of the supply chain mainly focuses on cost, quality, and on-time delivery. An entrepreneurial supply chain, on the other hand, adds growth and innovation to cost, quality, and delivery. Although cost, quality, and delivery are the key to success, in today's highly competitive market, they are not enough for the entrepreneurial supply chain (810). In this regard, the key role of the Red Crescent Society in the field of crisis management and the provision of social and sanitary needs of affected communities highlights the importance of entrepreneurial supply chain management.

This study can bridge the gap between theoretical research and its implementation as one of the critical needs in the field of post-disaster resource provision. Relief organizations, especially the Red Crescent, lack any specific entrepreneurial strategy and program for the production, identification, and distribution of relief supplies. These organizations mainly focus on the preparation and distribution of supplies in times of crisis.

In this regard, the present study aimed to design an entrepreneurial supply chain model with an emphasis on technology in 2020 in Iran. In other words, the present study considered the economic dimension in the field of crisis management and strengthening the components of prevention, preparedness, response, and rehabilitation through the supply chain as a new approach in the field of crisis management.

\section{Methods}

This exploratory study was performed in qualitative and quantitative phases. In the first phase, some indicators were obtained by observing the current situation and interviewing 30 experts. Following that, the final model was achieved by considering all indicators and categorizing the topics. In the Delphi process, interviewing experts and theoretical consensus suggested some hypotheses. In other words, in the second phase, structural equation modeling was used to finalize the model.

Both qualitative and quantitative data collection tools were designed and employed.

In the first stage, according to the content analysis method, the desired criteria were collected through open-ended questions and interviews. The experts, who were interviewed in the stages of the qualitative phase, including the Red Crescent experts, university professors, Red Crescent Society theorists, as well as relevant authors and researchers, were regarded as the statistical population.

In the present study, in the first stage, in order to determine the desired indicators, 30 cases were selected via snowball sampling and attended indepth interviews. The questions included "What aspects of the supply chain are most vulnerable in the event of a disaster? What solutions can be implemented?" "What criteria can be effective for the entrepreneurial supply chain in disasters?" The interview lasted between 30 and $120 \mathrm{~min}$, took place in a quiet place, and ended with data saturation. Immediately after the interviews, the 
interview was transcribed, the criteria were extracted, and the data were manually analyzed. Thematic analysis method was used to analyze the interviews. It consists of 6 steps that were performed as follows:

A) Familiarization with data, b) development of initial codes, c) Search for categories and subcategories, d) Revision of categories and subcategories, e) Defining and naming categories and subcategories, and) Preparing a report (11). Lincoln and Guba's Evaluative Criteria (12) were used to ensure the accuracy of qualitative data. Finally, the designed questionnaires were provided to 30 experts to determine the importance of the criteria according to the Delphi technique with a five-point Likert scale ranging from very low to very high.

In the second stage, based on the results of the interviews, a data collection questionnaire was designed with closed-ended questions rated on a Likert scale. The desired information was collected by the administration of the questionnaire to 186 people working in the Red Crescent Society. The validity and reliability of the questionnaire were measured by Bartlett's test of Sphericity and Kaiser-Myer-Olkin (KMO) to determine factor analysis and sampling adequacy. After the identification of the main indicators of the supply chain with emphasis on entrepreneurship, a list of all senior managers of the Red Crescent was prepared and they were randomly selected according to the total number of the statistical population consisting of senior and middle managers.

The goodness of fit of the model was determined by the chi-square divided by the degrees of freedom $(\chi 2 / \mathrm{df})$, Adaptive Fit Index (CFI), the goodness of fit index (GFI), Adjusted Goodness-of-Fit Index (AGFI), NFI (Normed Fit Index), Non-Normed Fit Index (NNFI), Root Mean Square Error of Approximation (RMSEA). LISREL software was also used to create a structural equation model. All ethical considerations were taken into account. Data analysis was performed in SPSS software (version 23) and Lisrel (version 8.8).

\section{Findings}

In-depth interviews were conducted on 30 semi-structured subjects. The mean age of experts was reported as 46 years, and 21 of them were male. After analyzing and extracting the criteria from the interviews, 186 codes were retrieved which yielded the components of the model. Two questionnaires were designed. The first questionnaire was about supply chain management encompassing four main components of customer integrity, supplier integrity, internal integrity, and innovative orientation.

The initial questionnaire comprises 20 items. The second questionnaire is related to technology including seven components: personal characteristics, attitudinal factors, educational factors, technical factors, economic factors, environmental factors, as well as human and managerial factors. The initial questionnaire contains 60 items. After the implementation of the Delphi technique and the administration of the questionnaire to the same 30 experts who were interviewed, the number of approved items is displayed in Table 1.

After confirming the final questionnaire, for each component, the two items with the highest score were included in the model. In the next stage, the final questionnaire was provided to 186 Red Crescent employees, 169 of whom were male. The highest age range of employees $(n=94)$ was 41-50 years. In terms of education, 59 92, and 35 cases had a bachelor's degree, a master's degree, and a $\mathrm{PhD}$. After the completion of the questionnaires, the structural equation method

Table 1. Initial designed questionnaire and the number of items approved after the Delphi technique

\begin{tabular}{|c|c|c|}
\hline \multicolumn{3}{|c|}{ Supply Chain Management Questions(first step) } \\
\hline Indicator & $\begin{array}{l}\text { Number of } \\
\text { initial items }\end{array}$ & $\begin{array}{l}\text { Number of } \\
\text { verified items }\end{array}$ \\
\hline Customer integrity & 5 & 4 \\
\hline Supplier integrity & 5 & 3 \\
\hline Internal integrity & 5 & 2 \\
\hline Innovative approach & 5 & 3 \\
\hline
\end{tabular}

\begin{tabular}{|c|c|c|}
\hline \multicolumn{3}{|c|}{ Technology questions (first step) } \\
Indicator & $\begin{array}{c}\text { Number of } \\
\text { initial items }\end{array}$ & $\begin{array}{c}\text { Number of } \\
\text { verified items }\end{array}$ \\
\hline $\begin{array}{c}\text { Individual } \\
\text { characteristics }\end{array}$ & 11 & 4 \\
Attitudinal factors & 13 & 4 \\
Educational factors & 8 & 3 \\
Technical factors & 7 & 3 \\
Economic factors & 6 & 3 \\
Environmental factors & 8 & 4 \\
Human and managerial & 7 & 3 \\
\hline factors & & 3 \\
\hline
\end{tabular}

Table 2. Results of KMO index and Bartlett Sphericity

\begin{tabular}{ccc}
\multicolumn{3}{c}{ Kaiser-Meyer-Olkin Measure of Sampling } \\
Adequacy. & .715 \\
Bartlett's Test of & Approx. Chi-Square & 736.764 \\
Sphericity & df & 231 \\
& Sig. & .000 \\
\hline
\end{tabular}


was used for data analysis. The results of the KMO index and Bartlett Sphericity are depicted in Table 2.

Considering the KMO value $(>0.7)$ and the significant number of Bartlett Sphericity test, it can be concluded that the data are suitable for factor analysis. The results of the goodness of the model are illustrated in Table 3. The model fit values exceeded 0.9 , indicating that the model has a "good fit.

The results of path coefficients and significance among research variables are presented in Table 4 and Figure 1. The results demonstrated that the path coefficients were significant for seven relationships at the level of 0.05 .

Table 3. Results of the goodness of the final model

\begin{tabular}{cccc} 
Goodness of fit index & Acceptable range & Value & Result \\
\hline chi-square divided by the degrees of freedom $(\chi 2 / \mathrm{df})$ & $<3$ & 2.74 & Good \\
Adaptive Fit Index (CFI) & $>0.9$ & 30.9 & Good \\
goodness of fit index (GFI) & $>0.9$ & 60.9 & Good \\
Adjusted Goodness-of-Fit Index (AGFI) & $>0.9$ & 10.9 & Good \\
Normed Fit Index (NFI) & $>0.9$ & 40.9 & Good \\
Non-Normed Fit Index (NNFI) & $>0.9$ & 0.93 & Good \\
Root Mean Square Error of Approximation (RMSEA & $<0.08$ & 0.07 & Good \\
\hline
\end{tabular}

Table 4. Results of direct relationship and significance coefficients of model

\begin{tabular}{ccccc}
\hline Path & Item & Path coefficient & Sig. & Test results \\
\hline Personal characteristics --- supply chain & IC - SC & 0.48 & 2.13 & Confirmed \\
Attitudinal factors --- supply chain & AF - SC & 0.44 & 2.06 & Confirmed \\
Educational factors --- supply chain & EF - SC & 0.53 & 2.69 & Confirmed \\
Technical factors --- supply chain & TF - SC & 0.61 & 3.45 & Confirmed \\
Economic factors --- supply chain & ECF -- SC & 0.55 & 2.37 & Confirmed \\
Environmental factors --- supply chain & ENF -- SC & 0.57 & 3.01 & Confirmed \\
Human and managerial factors --- supply chain & HMF -- SC & 0.59 & 3.11 & Confirmed \\
\hline
\end{tabular}

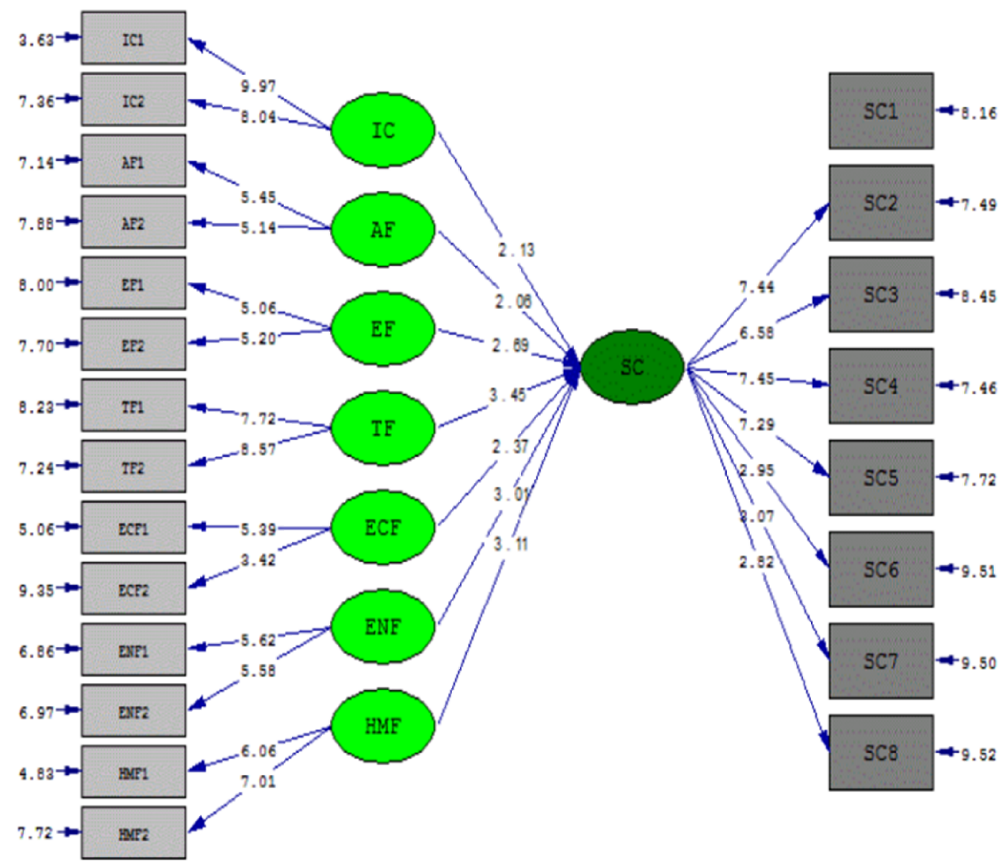

Figure 1. Structural research model showing the significance of relationships

\section{Discussion and Conclusion}

The present study aimed to develop an entrepreneurial supply chain model in disaster response in Iran. The revision of related studies conducted in Iran and the world yielded no study 
or model on the entrepreneurial supply chain in disaster response. Therefore, similar studies were reviewed. Attitudes, education, personal characteristics of individuals, economic, as well as environmental and technical factors, all have a direct impact on the entrepreneurial supply chain in disaster response.

The promotion of cultural, social, and economic skills can help a resilient supply chain. Supply chain management as a practical approach can be effective in the provision and optimization of economic resources in various processes, such as crisis management and provision of the social, health, medical, and other needs of the affected community. It is worth noting that the traditional view of the supply chain mainly focuses on cost, quality, and on-time delivery. An entrepreneurial supply chain, on the other hand, adds growth and innovation to cost, quality, and delivery.

Although cost, quality, and delivery are the key to success, in today's highly competitive market, they are not enough for the entrepreneurial supply chain (8-10). In this regard, the key role of the Red Crescent Organization in the field of crisis management and the provision of social and sanitary needs of affected communities highlights the importance of entrepreneurial supply chain management. The supply chain is defined as a system encompassing four processes: plan, resource, provision, and delivery. In general, supply and demand planning, raw material supply, production planning, inventory control, warehousing, product distribution, and information management are among the activities performed in the field of the supply chain.

In this regard, the supply chain is affected by various factors, such as employees' characteristics. Although based on theoretical data, education, behavioral and psychological characteristics, and work experience are regarded as individual characteristics. The effective individual factors should be identified and assessed in a study appropriate to the organization and profession in which the person is employed. Consequently, in today's fast-paced world, success is achieved in societies with skilled, dedicated, creative, and self-confident people. Since creative and innovative people as entrepreneurs have been the source of great changes in the field of industry, education, and services in the global arena.

An entrepreneur is someone who is a pioneer in innovation, giving birth to new processes, job opportunities, and businesses (13). Attitude factors were discussed with an emphasis on technology as one of the effective indicators on the entrepreneurial supply chain of rescue and relief in the Red Crescent population. Understanding the attitude of entrepreneurs in any society can be of great help to a better understanding of the formation and consequences of entrepreneurial activities.

The great differences in the attitude of entrepreneurs in different countries raise questions about the most important evaluation indicators for attitudinal factors, and more importantly, the indicators and patterns reflecting attitudinal factors in the Iranian Red Crescent. This issue needs to be examined from the perspective of the managers, deputies, and experts of the Red Crescent Society.

The identification of attitudinal factors affecting the entrepreneurial supply chain is mainly performed in Delphi methods and interviews based on consensus among the elites. The attitude of the Red Crescent staff towards new technologies can determine the direction of their activities in the supply chain. According to experts, evaluating Internet usefulness, information exchange, and measuring the necessity of the Internet have been selected as appropriate criteria for the assessment of attitudinal factors from the perspective of Red Crescent staff.

As long as a member of the Red Crescent Society has a positive and dynamic attitude towards entrepreneurial activities, there will definitely be an effective growth and chain in the organization. The Red Crescent Society of the country can definitely play a prominent role in the Red Crescent entrepreneurial supply chain by changing employees' attitudes towards technology using educational and infrastructure tools.

A study entitled "An integrated disaster relief supply chain network model with time targets and demand uncertainty" was conducted by Anna Nagurney et al. in 2013. Increasing the incidence of natural disasters and their devastating impact requires effective preparedness against them. The current study investigated an optimal disaster relief supply chain network model in the field of transportation and distribution of relief supplies for vulnerable areas.

The system optimization is performed considering all operating costs associated with the supply chain network for unwanted demands. 
They also provided solution algorithms for the model and used goal-based planning to minimize times in the routes before setting delivery time targets (14). A study entitled "A novel approach for inventory problem in the pharmaceutical supply chain" was conducted by Gökçe Candan et al. in 2016. Proper supply chain management policies are an essential prerequisite for staying in the financial markets in the pharmaceutical industry.

Classic supply chain models are usually demand-driven. The present study designed a new mathematical model to solve the problem of investment in the pharmaceutical supply chain. This problem was formulated with mixed-integer linear programming (MILP) aiming at obtaining the maximum net profit. The effectiveness of the proposed model was tested using two methods of classical supply chain and vendor-managed inventory (VMI). Finally, the mathematical model was assessed with other existing models and the optimal model was presented (15).

A study entitled " Developing a suitable model for supplier selection based on supply chain risks: an empirical study from Iranian pharmaceutical companies " was carried out by Mehralian et al. in 2011. The supply chain establishes a link between new product development and the pharmaceutical market. The present study aimed to formulate the key factors in risk analysis of the pharmaceutical industry and determine and prioritize the factors affecting supplier selection.

This study used the existing articles, expert opinion, statistical analysis, the fuzzy TOPSIS (Technique for Order Preference by Similarity to Ideal Solution), and multiple attribute decision making (MADM) model in data collection and distribution of questionnaires. Risk factors were formulated based on statistical results and the MADM model. The results demonstrated that reducing the risk of product delivery can be effective in the reduction of risk in the pharmaceutical industry (16).

A study entitled " Before and after disaster strikes: a relief supply chain decision support framework " was performed by Sameer Kumar et al. in 2013. The potential and extent of damage caused by natural disasters cannot be measured in many cases. In addition, the risks posed to societies are on the rise as the world's population grows. The mentioned study evaluated the framework for managing risks in a disaster relief supply chain. This framework was applied to the example of the 2011 Tsunami in Japan, a nuclear power plant accident.

Identification and quantification of risks at different stages of the supply chain was calculated and entered into the model using Fault tree analysis (FTA) and Failure Mode, Effects \& Criticality Analysis (FMECA). Thereafter, the mind map of response, communication, resource replacement, procurement, and transfer was drawn. The development of a program and a strong communication system in the coordination of all groups before, during, and after disasters will lead to effective responses (17).

Today, due to the importance of economic activities with an entrepreneurial approach, the selection and adoption of paradigms and practical approaches in the economic field plays a peculiar role in the positive results and effective performance of the Red Crescent Society. To achieve a sustainable supply chain, the strategic level is one of the best steps to consider sustainability criteria. Supply chain management as a practical approach can be effective in the provision and optimization of economic resources in various processes, such as crisis management and provision of the social, health, medical, and other needs of the affected community.

Supply chains are considered a suitable platform for entrepreneurship due to the involvement of different sections of Iran Red Crescent Society in joint activities. The expansion of entrepreneurship issues in the supply chain highlights the necessity of presenting a comprehensive model of the entrepreneurial supply chain in the Red Crescent with an emphasis on the technology component. In today's competitive environment, supply chain management is of paramount importance for the Red Crescent to achieve success and competitive advantages.

In this regard, according to research findings, as well as the views of managers, deputies, and experts of the Red Crescent Society, it can be concluded that entrepreneurial supply of relief and rescue in the Red Crescent population with emphasis on technology needs assiduous attention to human and managerial, environmental, economic, technical, educational, and attitudinal factors, as well as personal characteristics. Among the mentioned components, environmental factors, as well as managerial and human factors, played the most prominent role in the 
development of the entrepreneurial supply chain, as compared to other indicators.

Finally, the development of an entrepreneurial rescue supply chain would not be possible without considering the influential factors assessed in the present study. The use of entrepreneurial approaches in the disaster supply chain makes relief operations more effective. Among the limitations of the present study was, one can refer to lack of access to all experts, and attempts were made to select those with maximum knowledge and experience. Moreover, the current study was merely conducted in the Red Crescent Society, and the results may be different in other relief organizations.

The supply chain in disaster response requires experts' comprehensive approach and innovative perspective. The tendency of countries to take innovative measures in disasters requires macropolicies at the national and regional levels. Therefore, all dimensions and aspects of the entrepreneurial supply chain in disasters must be considered in order to attain the final goal which is effective and efficient disaster management.

\section{Acknowledgments}

\section{None}

\section{Conflict of Interests}

Authors have no conflict of interests

\section{References}

1. Naderi N, Mohammadi J. Locating temporary housing after the earthquake, using GIS and AHPTechniques (A case study: 15 districts of Isfahan City). J Soc Issues Human 2015; 3(12): 71-5. (In Persian).

2. Asgari A. In the search of management and planning principals. International Congress of Crisis Management in Disasters, Tehran, Iran; 2007 (In Persian).

3. Yu M, Yang C, Li Y. Big data in natural disaster management: a review. Geosciences 2018; 8(5): 165.

4. Seeger MW, Ulmer RR, Novak JM, Sellnow T. Post-crisis discourse and organizational change, failure and renewal. J Organ Change Manag 2005; 18(1): 78-95.
5. Kusi-Sarpong S, Gupta H, Sarkis J. A supply chain sustainability innovation framework and evaluation methodology. Int J Prod Res 2019; 57(7): 19902008.

6. Liao $\mathrm{SH}, \mathrm{Hu}$ DC, Ding LW. Assessing the influence of supply chain collaboration value innovation, supply chain capability and competitive advantage in Taiwan's networking communication industry. Int J Prod Econ 2017; 191: 143-53.

7. Seman NA, Govindan K, Mardani A, Zakuan N, Saman MZ, Hooker RE, et al. The mediating effect of green innovation on the relationship between green supply chain management and environmental performance. J Cleaner Product 2019; 229: 115-27.

8. Hahn GJ. Industry 4.0: a supply chain innovation perspective. Int J Product Res 2020; 58(5): 1425-41.

9. Heaslip G, Kovács G, Haavisto I. Innovations in humanitarian supply chains: the case of cash transfer programmes. Product Plan Control 2018; 29(14): 1175-90.

10. Wang M, Asian S, Wood LC, Wang B. Logistics innovation capability and its impacts on the supply chain risks in the Industry 4.0 era. Modern Supply Chain Res Appl 2020; 2(2): 83-98.

11. Braun V, Clarke V. Using thematic analysis in psychology. Qualit Res Psychol 2006; 3(2): 77-101.

12. Schwandt TA, Lincoln YS, Guba EG. Judging interpretations: but is it rigorous? Trustworthiness and authenticity in naturalistic evaluation. New Direct Evaluat 2007; 2007(114): 11-25.

13. Altay N, Gunasekaran A, Dubey R, Childe SJ. Agility and resilience as antecedents of supply chain performance under moderating effects of organizational culture within the humanitarian setting: a dynamic capability view. Product Plan Control 2018; 29(14): 1158-74.

14. Nagurney A, Masoumi AH, Yu M. An integrated disaster relief supply chain network model with time targets and demand uncertainty. Regional Sci Matters 2015; 7(15): 287-318.

15. Candan G, Yazgan HR. A novel approach for inventory problem in the pharmaceutical supply chain. DARU J Pharm Sci 2016; 24(1): 1-16.

16. Mehralian G, Gatari AR, Morakabati M, Vatanpour H. Developing a suitable model for supplier selection based on supply chain risks: an empirical study from Iranian pharmaceutical companies. Iran J Pharm Res 2012; 11(1): 209-19 (In Persian).

17. Kumar S, Havey T. Before and after disaster strikes: a relief supply chain decision support framework. Int J Product Econ 2013; 145(2): 613-29. 